Dossiê: Judaísmo: religião, cultura, nação - Artigo Original (c) $\underset{\mathrm{EY}}{\mathrm{B}}$

\title{
Da identidade religiosa: a singularidade judaica em Belo Horizonte em tempos de migração
}

\author{
From the religious identity: the Jewish uniqueness in Belo Horizonte in times \\ of migration
}

\author{
Júlia Calvo* \\ Amauri Carlos Ferreira **
}

\begin{abstract}
Resumo
$\mathrm{O}$ artigo discute e analisa a identidade religiosa judaica a partir do marco da diáspora que originou comunidades novas, marcadas por diferenças linguísticas, religiosas, históricas e culturais. A identidade judaica e sua configuração no campo religioso constitui na trama do simbólico o que é ser judeu em qualquer lugar do mundo, conduzindo a ideia de um povo /nação. Para entender o processo identitário do povo judeu foi necessário um contexto republicano. A capital mineira em sua fundação experimentou uma diversidade de povos migrantes judeus de diversas partes do país. Na formação da comunidade prevaleceram os judeus migrantes do Leste europeu responsáveis pelas primeiras organizações religiosas e comunitárias na cidade. A partir da década de 1930, principalmente com o aumento do antissemitismo europeu, a cidade passou a receber um outro grupo que trouxe novas contribuições para os judeus belo-horizontinos, ampliando a influência cultural e política, evidenciando uma singularidade no modo de ser judeu. O caminho escolhido para entender esse processo identitário e de singularidade foi o histórico.
\end{abstract}

Palavras-chave: Belo Horizonte; imigração; judaísmo; identidade religiosa; singularidade.

\begin{abstract}
The article discusses and analyzes the Jewish religious identity from the frame of the diaspora that led to new communities, characterized by linguistic, religious, historical and cultural differences. The Jewish identity and its configuration in the religious field constitute the symbolic plot of what it means to be a Jew anywere in the world conducting the idea of people/nation. To understand the identitary process of the Jewish people it was necessary a Republican context. Belo Horizonte, the capital of Minas Gerais, Brazil, in its foundation experienced a diversity of Jewish migrant people from various parts of the country. In the community formation prevailed the Jews from East European migrants responsible for the first religious organizations and community in the city. From the 1930 's, especially with the increase of European anti-Semitism, the city began to receive another group that brought new contributions to the Jewish in Belo Horizonte, broadening cultural and political influence by highlighting a uniqueness in being Jewish. The chosen path to understand this process of identity and uniqueness was based on history.
\end{abstract}

Keywords: Belo Horizonte; immigration; judaism; religious identity; uniqueness.

\footnotetext{
Artigo submetido em 25 de fevereiro de 2019 e aprovado em $\quad 30$ de abril de 2019.

* Doutora em Ciências Sociais. Professora da PUC Minas. País de origem: Brasil. E-mail: juliacalvo1@gmail.com

** Doutor em Ciências da Religião (UMESP). Professor de Filosofia da PUC- Minas e do Instituto Santo Tomás de Aquino - ISTA. País de origem: Brasil. E-mail: mitolog@pucminas.br
} 


\section{Introdução}

O judeu é reconhecido pelos seus pares em qualquer lugar do mundo a partir de sua inserção na comunidade. Tal inserção tem na religião um elo de identificação do ser judeu, que pode ser compreendido a partir do movimento americano da reforma judaica ao se tentar redefinir o termo judeu ${ }^{1}$. Belo Horizonte criou um padrão comunitário formado por condições próprias que têm relação com o contexto da cidade. A cidade estava em processo de ocupação quando os judeus chegaram. Estudar os judeus na capital mineira é traduzir a representação de uma cidade nas primeiras décadas do século XX como um espaço singular no contexto nacional que acabaria por reafirmar a noção republicana.

Essa reafirmação ocorreu pela configuração da cidade como espaço do novo. Um novo de fato, erguido pelas mãos dos diferentes grupos que aqui se constituíram e que, juntos com a cidade, foram se moldando na solução dos paradoxos presentes à época de sua fundação. Um espaço partilhado por tantas línguas e culturas que consagrou, mesmo talvez sem planejar, o espaço da liberdade e da igualdade jurídica e da defesa do bem público/comum.

Nessa configuração da cidade republicana com novos modos de vida um processo identitário se constitui. Os judeus conferiram à cidade de Belo Horizonte uma identidade. A identidade judaica é um dos pilares da permanência dos judeus como judeus em Belo Horizonte e no mundo. A vinculação étnica do grupo de judeus constitui valores comuns que perpetuam uma noção de pertencimento intra e extra grupo. Ou seja, permite uma definição do judeu, e seu consequente reconhecimento dentro do grupo, como também a percepção pela sociedade mais ampla, configurada em um grupo determinado por semelhanças entre si e particularidades que os diferem dos demais.

\footnotetext{
1 O termo judeu para incluir, além de convertidos, qualquer pessoa de descendência judaica, seja essa descendência matrilinear (posição da halachá) ou patrilinear (excluída pela halachá), que pratique o judaísmo e se identifique como judeu. É impossível, portanto, chegar a uma definição estrita do que vem a ser judeu (METZGER; COOGAN, 2002, p. 175). Nesse artigo ressalta-se que é judeu aquele que se identifica e que é identificado como judeu por seus pares, em Belo Horizonte e em qualquer lugar do mundo.
} 
Esse artigo tem como pressuposto ${ }^{2}$ uma singularidade no modo de ser judeu na cidade de Belo Horizonte, em que uma identidade não somente religiosa se afirma. O caminho escolhido para essa discussão é o histórico, em que se discute a relação religião e cidade, conferindo nos estudos sobre identidade religiosa os modos de ser e pertencer ao mundo.

Para compreender o ser judeu parte-se de uma discussão sobre a construção da identidade judaica e a singularidade de ser judeu na cidade de Belo Horizonte, Minas Gerais.

\section{A construção da identidade religiosa judaica}

A identidade funciona como uma referência dentro do mundo social que define objetivamente a localização do ser e do estar no mundo. A localização desse “eu” passa a ser central como categoria de análise de povo/nação que define a percepção de pertencimento. Ser judeu por ele mesmo e pela percepção dos outros ao longo do tempo em uma situação da diáspora, torna o grupo coeso, ligado a vínculos de uma mesma história e de pertencimento e, principalmente, alcança um status de comunidade. Paradoxalmente, cada grupo, dependendo da localidade em que se estabelece atualiza seus valores judaicos em relação à recepção da sociedade maior e à situação que se encontra diante do contexto, conjuntura, dimensão e outro, e, assim, forma também comunidades distintas e independentes.

A identidade do ser judeu não ocorre somente na religião que efetivamente se tornou o primeiro elemento de coesão do grupo. O sentido religioso do judaísmo está pautado no princípio da aliança (em hebraico brit) do povo com Deus. Esse princípio funcionou como definição, limites e como regulador e restritivo (ou fator

\footnotetext{
${ }^{2}$ Esse pressuposto tem sua origem na tese de doutorado de Calvo (2014), Entre Fazer a América e construir a cidadania: os judeus em Belo Horizonte nas primeiras décadas do século XX, que se constituiu num esforço em discutir Belo Horizonte como um caso singular para atração e fixação dos migrantes judeus durante as primeiras décadas do século XX, entre 1910 e 1940 . Compreende formas de inserção à cidade que se relacionavam ao contexto da capital mineira ainda em processo de formação e se apresentava e traduzia um imaginário republicano, afirmado como discurso, e que, para o judeu, que passou a residir na cidade, criava-se uma expectativa de oportunidade de enriquecimento e mobilidade social definida pela expressão "Fazer a América", ao mesmo tempo em que consolidava possibilidades de integração que se aproximavam do desejo de emancipação do grupo judaico, que já se havia concretizado em al guns países da Europa e nos Estados Unidos com a implementação de condições jurídicas mais igualitárias para inclusão dos judeus e que, em Belo Horizonte, abria-se para o ideal de construir a cidadania (adaptado de CALVO, 2014, p. 8).
} 
anti-assimilatório) dos grupos judeus no convívio com outros povos que mantiveram contato3 (CALVO, 2014, p. 108). Assim, compreendemos os judeus como um grupo étnico que estabelece um novo tipo de identidade em mudança, que conserva uma configuração religiosa e que os mantém coesos e fiéis às suas crenças.

No judaísmo, a religiosidade implica na necessidade de constituição de um grupo. Para efetivar a leitura da Torá (o livro sagrado do judaísmo) são exigidos no mínimo 10 judeus (tradicionalmente homens que já tenham sua maioridade judaica), nos quais a sinagoga expresse o modo de ser judeu (CALVO, 2014, p. 108). A sinagoga, entretanto, precisa ser compreendida como um espaço, que tem a função da demarcação de um território judaico para as comunidades judaicas espalhadas pelo mundo. É no espaço da sinagoga que o modo de ser judeu se consolida em seu aspecto religioso.

Para além de um espaço de orações, um templo, um local para o serviço religioso, a sinagoga é o espaço de congregação relacionado às especificidades no campo religioso e cultural. Um local de aprendizado, desenvolvimento de estudos e de vínculos comunitários. Nos diferentes grupos, a noção de pertencimento a um grupo coeso é fundamental, porque é portadora de uma identidade reconhecida entre eles próprios, com a demarcação de um território e de uma comunidade. A comunidade, por sua vez, só se tornou possível como fruto de um ideal emancipatório, tendo em vista que cada comunidade representa a própria congregação que implica formas de lidar com o outro e com os tempos do outro.

Nesse sentido, cada comunidade é uma e, como as comunidades são organizadas diferentemente pelo mundo, a sinagoga também vai recebendo espaços e significados diferentes. Tomando como exemplo a sinagoga dos Estados Unidos, Geiger reflete que:

\footnotetext{
${ }^{3}$ A crença e tradição da aliança, do pacto com Deus, manteve o povo como seguidor da religião judaica, na defesa da crença em um Deus único e que não poderia ser representado por estátuas, rejeitando outras religiões e mantendo-o unido.
} 
[...] Lá a sinagoga seria, com maior frequência, a base para a localização de outras atividades institucionais para a vizinhança, como para ensinar hebraico, promover recreação etc. A diferença pode também ser observada no grau de centralização ou descentralização na organização das instituições. A vida política brasileira e sua estrutura institucional são, tradicionalmente, altamente centralizadas e hierarquizadas, enquanto os Estados Unidos guardam a tradição da profunda descentralização e forte autonomia dos poderes estadual e local. (GEIGER, 2005, p. 295).

Enquanto "Lá", nos Estados Unidos, a sinagoga ganha status de espaço institucional, aqui no Brasil a sinagoga ganha mais espaço social, dividindo seu papel congregador e identitário com outras instituições judaicas. As comunidades judaicas brasileiras mantiveram suas tradições religiosas por muito tempo no espaço privado (das casas e, às vezes, de estabelecimentos comerciais). Não se construiu, em torno da sinagoga, um espaço de representação, mas da perpetuação da tradição religiosa em um "novo" espaço, sob a ótica do judeu migrante.

Já a vida social e sua ligação do judeu residente no Brasil e em Belo Horizonte com a sociedade mais ampla se deu a partir da cultura do outro, por meio da criação de espaços de convívio social na criação de clubes recreativos, que em Belo Horizonte especificamente já constituíam uma prática na cidade (JULIÃO, 1996). Esses grupos é que mantinham a sinagoga, além de outros espaços de referência cultural e social.

Como espaço religioso, a sinagoga, no caso de Belo Horizonte, foco deste artigo, reunia judeus principalmente no período das grandes festas de mais importância religiosa. Os demais aspectos culturais como a educação, a socialização e a recreação comunitárias eram mantidos pelo clube no seu privado salão de festas, biblioteca, grupo de teatro ídiche (CALVO, 2014) e com a acomodação das entidades que se formaram para reunião de pessoas para cuidar dos assuntos comunitários (escola, cemitério, assistência e festejos).

É por essas marcas diferenciadoras entre as comunidades judaicas que se formaram pelo mundo e sua relação com a sociedade mais ampla onde se localizava que investigar a identidade judaica tornou-se uma complexidade às vezes de difícil compreensão. Daí que se prefere adotar o conceito de fronteiras étnicas de Fredrik 
Barth (1997). Elas são determinadas por forças que agem do interior para o exterior, cuja significação varia em relação aos interesses e valores que os atores lhes conferem. Ou seja, é na interação com a sociedade mais ampla e considerando a conjuntura e os mecanismos internos e externos que os atores poderiam optar por ampliar ou reduzir seus limites redefinindo suas fronteiras.

Ao refletir sobre os judeus, principalmente quando associados às comunidades mais ortodoxas com visível diferenciação cultural, se imagina a identidade judaica como tradição. A tradição é um dos componentes da identidade judaica, porque manipula valores como história, origem em comum, experiências de perseguição, extermínio e segregação entre outras memórias associadas, mas não é por si só a determinação da identidade judaica, visto que os grupos de judeus atualmente do mundo são marcados por uma diversidade cultural, religiosa, linguística.

Considera-se, assim, o judeu como grupo étnico capaz de compartilhar valores comuns que os tornam portadores de uma cultura, de uma tradição e que os distinguem de outros. Grupos étnicos assim são vistos naquilo que lhes é socialmente efetivo como forma de organização social, considerando a auto atribuição ou a atribuição por outros de pertencimento. Tal perspectiva é entendida dentro da Antropologia Social como uma organização política informal e social específica, pautada na construção simbólica que se contrasta à sociedade hegemônica envolvente, e que, como categoria étnica, tem seus membros identificados e identificando-se pelo partilhar de uma história e uma tradição particulares (CUNHA, 1986).

Barth, nos anos 1970, analisava a persistência dos grupos étnicos questionando os postulados que foram adotados até o período de seus estudos que foram configurados em três: a persistência se dá através da diferenciação dos outros grupos; a persistência se dá pelo isolamento geográfico; a persistência se dá pelo isolamento social. No entanto, nenhum deles é suficiente para explicar a perpetuação do grupo judaico. 
O argumento de Barth (1997) era de que os limites dos grupos étnicos perduraram apesar do trânsito entre os diversos grupos, como no caso dos judeus e nos permite, a partir da tese do autor, compreender o fenômeno dos grupos étnicos e seu lugar nas sociedades e nas culturas humanas, nas fronteiras étnicas. Ou seja, nas fronteiras sociais do grupo e não na cultura (antes valorizada na literatura), constituída na interação entre as pessoas. A cultura é vista assim como produto das diferenciações étnicas, historicamente e perpetuamente elaborada para além da percepção de que os grupamentos humanos são diferentes, de como são construídos os limites desses grupos ao longo do tempo e de acordo como o dinamismo social que eles compartilham.

Com relação à identidade judaica, comparada às demais, é preciso destacar que as conjunturas históricas de perseguição e segregação foram elementos de distinção importantes, que ampliam a vinculação do grupamento judaico para além da religião. Não existe ex-judeu, mesmo diante da possibilidade da adoção de outras religiões dentro do grupo (judeus que se converteram ao cristianismo, às religiões evangélicas, ao espiritismo, por exemplo). O ser judeu se configura em uma identidade que se inscreve no corpo independente de sua religiosidade.

Maffesoli (1987) destaca essa inexistência em contraposição à concepção de mudança que existe em outras religiões, mas inexiste na religião judaica. Por força endógena ou exógena o judeu continua sendo sempre judeu4. A discussão do que é ser judeu está na literatura repleta de convergências e contradições. Destaca-se a origem histórica e as perseguições como em Pinsky (1997) e Blay (1997) também considera a influência da modernidade na tradução do judaísmo comunitário em Sorj e Grin (1997), considera a Lei judaica (Halachá) como ligação matrilinear ou de auto definição e identificação como em Goldman (1984) e Benchimol (1998) e ainda reflete sobre a contemporaneidade de ser judeu com Lewin (1997) e Sorj (1993), que avançam nos sistemas de compreensão do ser judeu no mundo hoje.

\footnotetext{
${ }^{4}$ Durante a Inquisição Ibérica no século XVI (definida nos estatutos de pureza de sangue) e o Nazismo (definição de raça judia) no século XX, bastava 1/4 de sangue judeu, ou seja, parente de quarta geração para demarcar o limite da perseguição.
} 
Para Lewin (1997) são três dimensões fundamentais responsáveis pela característica da identidade judaica e sua perpetuação. São elas: a endogamia, a "solidariedade do exílio" e o "imperativo da memória". Ligadas à circulação dos sexos dentro do grupo para garantir a sua reprodução biológica, social, cultural e religiosa e a demarcação dos espaços; ao sentimento que leva cada uma das sociedades da diáspora a se fechar, para conservar seus traços religiosos e culturais. Tais exigências que significam o cumprimento de uma obrigação, estimulando cada judeu a ser responsável pela manutenção da identidade judaica como um todo; e ao transmitir o legado judaico às gerações subsequentes em uma socialização permanente presente no cotidiano da vida do judeu, respectivamente.

Para Sorj (1993), o caso brasileiro não se marca pelo antissemitismo como no universo europeu e ainda vivencia uma tradição de sincretismo religioso que abre espaço para receptividade, relativizando a própria discriminação do judeu. Para o autor, existe uma identidade judaico-brasileira diferente do restante da América Latina, construída em cima da própria realidade nacional que se mantém e se consolida em um sistema de valorização do ensino judaico, na solidariedade e no apoio ao Estado de Israel. Essa abordagem permite uma compreensão pósmoderna de ser judeu:

O judeu pós-moderno lembra do judaísmo em contextos particulares nascimentos e mortes, casamentos e Bar/Bat-mitzvá - e momentos especiais da trajetória pessoal - doenças, crises existenciais, etc. (...) Assim, o Judaísmo passou a ter um caráter modular, construindo um mix de acordo com o gosto individual geralmente com componentes soft, isto é, lembrando a tradição mas de forma não muito exigente - ser judeu se transformou no direito de passe livre ao consumo de sua tradição específica, o judaísmo. (SORJ, 1993, p. 16).

O critério da etnicidade, que engloba cultura e tradição, é assim fundante na constituição da noção de pertencimento e na particularização do migrante judeu. Nesse sentido, é importante considerar o fator diaspórico que marca a relação do judeu com o mundo desde a Antiguidade. 
O judeu se autodefine como povo. Um povo de tradição migratória internacional, como um povo da diáspora, ou seja, historicamente construído na dispersão. A história dos judeus é marcada pela saída em massa de um grupo, que deixou a Palestina espalhando-se pela Europa e norte da África e essa dispersão passou a traduzir a própria noção de ser do povo judeu (CALVO, 2014, p. 55).

Os judeus residiram em outras nações, se submetendo a formas diferentes de integração e de cidadania ao longo do tempo e do espaço. Nesse contato dos judeus com os nacionais dominantes surge o antissemitismo como construção coletiva. Uma forma discriminatória já que o judeu, por força grupal ou por força maior, na convivência com outros povos, manifestava cultura e tradição diferentes, que o destacam e que, gradativamente, passam a incomodar o outro, o não judeu.

Dessa discriminação veio a intolerância, relacionada ao incômodo e ao desconforto com o diferente, originando o medo e a ameaça da perda dos padrões nacionais. O revestimento negativo gradual da intolerância vai levar ao estabelecimento de um conceito negativo, preconcebido de geração a geração (preconceito), até a última fronteira, correspondente ao ódio irracional, sem explicação da origem ou possuidor de lógica que é o antissemitismo.

A tendência do migrante, judeu ou não, é manter sua religião de origem. No entanto, nem sempre isso é possível, devido ao processo transcultural das cidades e de acolher religiões diferentes daquela concebida no país. Se há dificuldades intrínsecas nesse processo, as migrações têm o poder de favorecer mudanças na própria religião ou nas religiões com as quais mantêm relação. $\mathrm{O}$ contato com contextos culturais diferentes leva a um estado de readaptação, gerando o que pode ser chamado de extensão da religião de origem ou, em alguns casos, de mitificação desse lugar. Nesse processo de saída de um lugar e entrada em outro emerge uma identidade em metamorfose, na qual pode ocorrer significação da tradição. E quando o povo estabelece sua identidade como nação sem o território? Essa indagação nos permite investigar os judeus em Belo Horizonte em sua origem e expansão da cidade. 


\section{Os judeus na fundação de Belo Horizonte}

Os judeus, assim como outros grupos externos, participaram da fundação 5 de Belo Horizonte, cidade construída para abrigar a nova capital do Estado de Minas Gerais, que reuniu pessoas vindas de todas as partes, a ponto de ser considerada por Botelho (2007) como uma cidade de migrantes.

Essa diversidade cultural e de origem, juntamente com o contexto de formação e o discurso de novidade, "modernidade" e de república é que vão contribuir para formar uma cidade que era, de fato, nova. Nova nos seus valores, nova na seleção do seu repertório, na escolha dos seus princípios racionalizantes e geométricos e nos anseios de tornar-se cidade de um século influenciado por uma urbanidade marcada pelo consumo de uma cultura e mercadorias pós era industrial.

Pensar isso é importante para, na comparação com os estudos de outras comunidades judaicas brasileiras, construir a noção de singularidade e especificidade dos judeus em Belo Horizonte. Inicialmente vamos categorizar o grupo na cidade: os judeus são importantes para a fundação e construção da cidade, mas não fundaram um espaço novo de participação política como comunidade judaica ${ }^{6}$ (CALVO, 2014, p. 173). É inegável, apesar dessa reflexão, que vai se consagrar um mito de fundação e que se materializa na valorização dos pioneiros da comunidade judaica.

Belo Horizonte recebeu os dois grupos com suas diferentes clivagens e cujas migrações têm marcas próprias. Na formação da comunidade prevaleceram os judeus migrantes do Leste europeu, de origem majoritariamente sefaradi,

\footnotetext{
${ }^{5}$ A cidade de Belo Horizonte, sob o nome inicial de cidade de Minas, construída para ser a nova capital do Estado de Minas Gerais, foi inaugurada em 12 de dezembro de 1897 a serviço de um ideal de ordenamento muito presente no vocabulário da burguesia mineira. Apesar do contexto de sua formação coincidir com a afirmação de uma recente república brasileira, associada ao rompimento da monarquia e dos valores que ela carregava, a cidade continuava conferindo a tradição e o conservadorismo ao perpetuar as barr eiras entre a elite e os setores populares.

${ }^{6}$ É importante destacar que a presença de judeus no Estado não é fruto da nova capital. Os judeus já registraram anteriormente sua presença em Minas Gerais. Segundo Póvoa (2009, p. 199) as primeiras cidades mineiras a receberem judeus foram: Ouro Preto, Mariana, Congonhas do Campo, São João Dei Rey, Sabará, Diamantina, Paracatu e Araxá, ligadas às atividades mineradoras de ouro e de pedras preciosas, nos séculos XVI e XVII.
} 
responsáveis pelas primeiras organizações religiosas e comunitárias na cidade. A partir da década de 1930, principalmente com o aumento do antissemitismo europeu, a cidade passou a receber o grupo ashkenazi, que trouxe novas contribuições para os judeus belo-horizontinos, ampliando a influência cultural e política (CALVO, 2014).

Destaca-se mais uma categoria importante na definição do judeu em Belo Horizonte: o judeu, nos países de origem e, no Brasil, foi com maior ou menor intensidade, considerado um estrangeiro, o que explica tanto as motivações de sua saída no caso de guerras e perseguições, como também, e principalmente, a adoção de formas de perpetuação identitária.

A situação de estrangeiro serve de base para uma análise da situação vivida por um grupo étnico em uma sociedade diversificada que, na análise de Pfeffer (1993), é tratado como um tipo sociológico ao partir da percepção de que existem identidades particulares que subsistem em sociedades plurais. Nesse mesmo sentido, Simmel (2005) 7 define o estrangeiro, na sua forma sociológica, como aquele que representaria a síntese de duas propriedades: se fixa num determinado grupo espacial, mas sua posição dentro dele é fundamentalmente afetada pelo fato de não pertencer inicialmente ao grupo.

Ao estudar os judeus em Belo Horizonte, Pfeffer considerou a situação de aproximação como novo grupo problemática, em que o estrangeiro, na interpretação de um novo modelo cultural com sua relativa concepção natural de mundo, tenderia à utilização de suas próprias referências ou de "seu pensar como de costume mesmo que o contato requeresse outro tipo de conhecimento".

Segundo o autor, essa necessidade de adaptação também é afetada pela questão da distância do grupo de origem e que, por isso, não permitiria a manutenção das relações, tais como se davam antes, baseadas no ambiente com objetos sociais do seu grupo. Isso significa que o estrangeiro tenderia a ficar ilhado,

\footnotetext{
${ }^{7}$ Texto retirado do livro de Georg Simmel: O Estrangeiro. Tradução de Mauro Guilherme Pinheiro KOURY. (SIMMEL, 2005, p. 265-271).
} 
sem os seus próprios referenciais já consolidados e sem poder utilizar os seus esquemas de orientação nem os do grupo aproximado (ficaria assim perdido entre “dois mundos").

Para Pfeffer, o judeu, ao romper seu isolamento com o contato na nova sociedade receptora, torna-se um membro do novo grupo, mas numa situação particular que necessita do estabelecimento de relações de reciprocidade, mas com estranhamento, enfatizando o que não é comum, já que esse estrangeiro no contato se colocaria próximo e distante ao mesmo tempo desse novo grupo (numa relação de aproximação e afastamento).

O judeu, no Brasil e no mundo, se organiza em comunidade. A noção de comunidade é importante para o grupo judaico desde a Antiguidade. Em várias partes do mundo é a congregação religiosa - a sinagoga - que concebe e materializa o vínculo comunitário. No Brasil as comunidades se organizaram em kehilot, ou kehilá, no singular, que significa comunidade ou congregação e era a forma de organização dos judeus no medievo frente às ameaças e às hostilidades (CARNEIRO, 2013).

A comunidade judaica de Belo Horizonte tinha uma identidade: os membros compartilhavam língua, religião, cultura, valores e articularam formas nítidas de pertencimento ao grupo e, com isso, pela sua singularidade, como grupo, e sua caracterização como estrangeiros, distinguiram-se dos outros grupos na cidade.

A fundação da ação comunitária é central para a organização do grupo e sua representação, e, depois de constituído, o ato da fundação precisa ser rememorado sempre que possível para preservação do próprio grupo.

No caso da comunidade de Belo Horizonte, os fundadores das principais associações coincidiram inúmeras vezes. O mesmo nome de um pioneiro da comunidade judaica de Belo Horizonte aparece como fundador de várias instituições pertencentes da comunidade judaica. Por exemplo, os fundadores da União Israelita de Belo Horizonte, a primeira instituição judaica da cidade, criada 
em 1922 foram: Arthur Haas, David Rochman, Rafael Arazi Cohen, Naftali Perlov, Saul Sadcovitz, Marcos Romischzv e Jaime Galinkin.

Muitos desses nomes se repetem na fundação da Escola Israelita (1928) e do Círculo Sionista (de 1930) e assim nas instituições que se seguiram ${ }^{8}$. Isso demonstra que eram as mesmas pessoas que participavam ativamente da comunidade judaica recém-criada e da sua continuidade (CALVO, 2014).

O registro dos fundadores permite a identificação das lideranças comunitárias, assim como a memória desses fundadores possibilita a concretização do passado para a comunidade e a definição de sua própria história. Os fundadores da comunidade judaica em Belo Horizonte são lembrados não só por suas ações, mas pelo seu perfil, como "homens bons", "homens que ajudavam muito os outros".

O que os torna fundadores é, em primeiro lugar, o seu pioneirismo. E nesse ponto são importantes como desbravadores e organizadores que garantiram, aos que vieram depois, um espaço já reconhecido e auxílio para adaptação. Em segundo lugar, as redes de sociabilidade que formaram em torno de si. Os fundadores atraíram com promessas, emprego ou ajuda, conterrâneos, parentes e amigos. Esses, por sua vez, continuaram a atrair conterrâneos, parentes e amigos, e assim sucessivamente.

Em terceiro e último lugar, constituíram-se na memória do grupo como "mito". Eles são considerados fundadores e lembrados pelas gerações posteriores como fundadores, mas dificilmente tiveram essa intenção. Eles vieram para Belo Horizonte em busca de oportunidades, de melhores condições. A criação de uma comunidade é uma consequência. Eles atraíam pessoas, porque precisavam de gente para cumprir os preceitos do judaísmo realizados no coletivo ou para

\footnotetext{
${ }^{8}$ Foram elaboradas e construídas listas a partir das atas e controle de pagamentos das instituições judaicas que existiram no período: União Israelita de Belo Horizonte, Damas Israelitas e sepultamentos no Cemitério Israelita. É interessante observar que os nomes aparecem muitas vezes com grafias diferentes, o que indica terem sido escritos por mãos diferentes, com compreensão diferente da fonética desses nomes e de sua própria escrita. A pronúncia e a compreensão do ídiche (utilizado na lista das damas israelitas) também interferem na grafia dos nomes relacionados. Essas listas constam na tese de doutoramento de um dos autores deste artigo.
} 
ampliarem suas frentes de trabalho. Mesmo não participando da fundação de uma comunidade intencionalmente, foram e são lembrados por isso.

Ao percorrer as instituições judaicas da capital mineira hoje, percebe-se que o registro dos fundadores está em todo lugar: em placas nas paredes, nas galerias de fotos, atrás das cadeiras na sinagoga. Tornaram-se mitos importantes para continuidade da comunidade e são reverenciados por isso.

As associações têm funções diversas tais como: manutenção da tradição; função política; vocação cívica; ou ainda função de reunir pessoas para o lazer ou para a formação de grupos para defesa de interesses. Nessas condições, a formação das entidades judaicas garantia pelo menos um ou todas essas formas associativas, como aconteceu em Belo Horizonte também.

A continuidade, entretanto, acabou por definir também heróis tratados assim na memória da comunidade. Esses heróis não se fizeram pela luta propriamente dita, mas pelo esforço de criar um espaço para os judeus na cidade e assim de prestar serviços importantes e essenciais, de preservar a religião e a cultura, de defender seus interesses, de prestar auxílio, de manter sua coesão e garantir sua preservação, de oferecer condições melhores aos migrantes que vieram depois e a seus descendentes9.

Os judeus em Belo Horizonte, no processo de adaptação ao espaço vivido, demarcaram um modo de ser judeu expressando suas crenças em uma cidade estritamente cristã e católica. Tal experiência pode se atribuir ao número não muito expressivo de judeus e a uma necessidade do comércio na cidade. Do ponto de vista religioso, ao se analisar as décadas de 1920 e 1930 do século XX, percebe-se que não há por parte da tradição católica ataques aos judeus de forma explícita. Nesses anos temos a ascensão de um catolicismo militante ${ }^{10}$ na cidade que busca combater

\footnotetext{
${ }^{9}$ Lembrar os fundadores é identificar as lideranças e dar à comunidade judaica uma história e o exercício vivo do direito à memória que mobiliza sentimentos de orgulho e pertencimento nas gerações posteriores a dos fundadores e nas que ainda estão por vir.

${ }^{10}$ Matos (1990, p. 395), ao fazer uma análise do catolicismo militante da década de 1920 a partir dos periódicos católicos de 1922-1936, disse que o combate aos inimigos estava circunscrito a protestantes, espíritas, comunistas, socialistas, moda indecente, carnaval.
} 
os inimigos. Os judeus não aparecem como inimigos da religião católica, mas os protestantes e os espíritas.

A importância dos judeus em Belo Horizonte é destacada no comércio da capital ao oferecer um nicho específico de acesso a produtos elegantes, marcadamente modernos, como eletroeletrônicos, mobiliário mais luxuoso, vestuário e seus complementos de moda como acessórios (gravatas, joias/bijuterias, guarda-chuvas etc.). É esse grupo responsável a dar um destaque à cidade sob um certo verniz moderno, de cidade do mundo, de serviços, produtos, princípios que inseriam a capital mineira no tempo de modernização e desenvolvimento brasileiro.

Essa participação do comércio vai ser uma das marcas da relação com a comunidade maior que garantiam a inserção desse grupo via utilidade e importância na construção da cidade e seus modelos. Associada ao discurso que a própria cidade consagrava para si de republicana, garantiram formas muito especiais de aceitação desse elemento na cidade e que garante a singularidade que analisaremos a seguir.

\section{A singularidade de um povo na capital mineira}

O desenho da singularidade passa pela ação do judeu no espaço público, respaldado na laicização do estado e na emancipação que se apoiava em um discurso inclusivo e de igualdade, mas, também e não menos importante, pelo destaque das possibilidades que a vinda desse elemento judaico trouxe à cidade como promessa modernizadora e de destaque para o país.

A partir das pesquisas de Calvo (2014), percebe-se que algumas características marcaram a participação do judeu em Belo Horizonte garantindo espaços de inserção. No cruzamento de listas dos associados em instituições judaicas (União Israelita de Belo Horizonte, Associação das Damas Israelitas e Cemitério) com os dados dos estabelecimentos comerciais de proprietários judeus na cidade, se descobriu que os judeus concentraram suas atividades comerciais em 
áreas determinadas da cidade, com destaque para os bairros onde residiam (Carlos Prates, Floresta e outros) e na área central de destaque para comércio da cidade ${ }^{11}$ que mostrou o maior número de residências.

Sob o volume de judeus na cidade, na análise demográfica, os números não impressionam. De acordo com o censo do IBGE de 1920, havia 4.824 estrangeiros em Belo Horizonte, incluídos aí os brasileiros naturalizados. Esse número sobe para 5.920 (ou 2,8\% da população) em 1940. De acordo com o censo, não é possível identificar os judeus, pois a declaração de religião só vai ser incluída a partir do recenseamento da população em 1940. Nesse censo, os israelitas constam como 791 em Belo Horizonte (ou 0,4\% da população).

O que chama a atenção não é exatamente a quantidade de judeus na cidade que vai aumentar muito nas décadas seguintes, principalmente após a Segunda Grande Guerra, mas a vinculação à representação judaica, principalmente à União Israelita de Belo Horizonte, o primeiro clube e entidade. Entre as décadas de 1920 e 1940, segundo a lista de associados, constavam 198 nomes. A associação ao clube era, como se esperava, voluntária e agregadora de famílias (aparecia só o nome do responsável, homem ou posteriormente viúva) e a participação e associação, necessário lembrar, ainda incluía uma contribuição financeira.

Em 1931 e 1932, segundo as listas de sócios da União Israelita, os judeus já somavam mais de uma centena. Nos livros de 1937 a 1941 já eram quase duas centenas e, se considerarmos o número de judeus que se declararam como israelitas (791 israelitas) e fizermos a comparação o número de associados da União Israelita de Belo Horizonte em 1940 (198 associados), significa que 25\% dos judeus, ou seja, um em cada quatro judeus na cidade, estava filiado à instituição representativa judaica existente no período (CALVO, 2014, p. 18). Esse número é significativo na indicação da organização, representatividade e participação dos judeus como grupo na capital mineira.

${ }^{11}$ Os dados e a análise estão disponíveis na tese de doutoramento de Júlia Calvo (2014). 
Com relação à ocupação do espaço público por meio do comércio, mais dados contribuem para indicarem caminhos dessa participação e visibilidade na cidade por meio da integração. A vocação de serviços da capital mineira já foi contemplada por Parreiras (2006) ao pontuar que, apesar de Belo Horizonte se voltar para uma formação capitalista com a adoção de mecanismos de reprodução do capital, e que vigoravam no contexto de sua construção, planejada para materializar e consolidar nos anseios de sua elite econômica e política, diferente de outras capitais tais como São Paulo e Rio de Janeiro, Belo Horizonte não se consagrou como uma cidade industrial, mas "desenvolveu-se cumprindo a sua missão de polo coordenador e se especializou como produtora de serviços" (PARREIRAS, 2006, p. 111) ${ }^{12}$.

Os judeus com seus nichos de comércio especializados contribuíram para fortalecer esse polo econômico e comercial ao oferecer serviços à população da cidade. Diferentemente do que aconteceu em outras capitais que concentraram judeus como Rio de Janeiro, São Paulo e Porto Alegre, o planejamento da cidade não constituiu um sectarismo espacial na formação de guetos ou de bairros étnicos. Em Belo Horizonte, os judeus compartilhavam a moradia com grupos de estrangeiros e de nacionais, sob variação de renda e classe social. Os bairros operários para os de menor poder aquisitivo e, à medida que a vida financeira permitia, concentrando-se em bairros com maior status social.

Essa concentração espacial dos judeus em determinadas áreas da cidade tem relação com a mobilidade social que a integração social e a participação econômica irão permitir ao judeu, de forma gradual, a concentrar-se mais na região central, indicando assim, um sentido de territorialização do grupo no espaço. A concentração espacial, considerada tanto a de trabalho como a de moradia, tem relação com o comércio. No centro da cidade estabeleceu-se um centro comercial -

\footnotetext{
12 Parreiras (2006, p. 120) analisa os dados comerciais de 1912 e 1920 e indica que no primeiro ano, 1.050 pessoas na cidade encontravam-se envolvidas no comércio, ou seja 10,2\%. Em 1920, este número ainda subiu para 2.055 pessoas, ou seja, $12 \%$ dos habitantes da cidade estavam envolvidos no comércio. Comparando a capital mineira nos seus anos iniciais e nos anos 1980 e 1990 , ela defende que ela cumpriu o papel para qual foi criada: "um centro dinâmico e articulador da economia mineira com vistas à integração do Estado no processo de modernização da economia capitalista".
} 
um triângulo para o comércio entre a antiga Avenida do Comércio (hoje Avenida Santos Dumont), a Rua dos Caetés ${ }^{13}$ e a Avenida Amazonas.

Dentro do próprio grupo judaico, a singularidade da cidade (nova e pouco populosa) permitiu também o entrosamento necessário para sua continuidade na criação de espaços para convívio social, de caráter privativo no caso da União Israelita, e a promoção de oportunidade e crescimento. Já que a cidade apresentava espaços que precisavam ser preenchidos, lacunas que necessitavam de mão de obra disponível, mas, acima de tudo, qualificada para dar sustentação ao projeto de infraestrutura urbana.

E os judeus vão ocupando essas lacunas, pois traziam um know how importante, fosse pelo domínio de uma outra língua, pelo conhecimento cultural e atitude cosmopolita, e a possibilidade de trazer e vender mercadorias importadas. Os judeus na cidade começaram a se especializar em setores específicos e tornaram-se referência na venda do que realçava o cliente e sua casa como indicaram os anúncios de época nos jornais e nas revistas (CALVO, 2014, p. 134).

A moda constitui uma introdução de novos hábitos, porém marcando paradoxos no ideal de modernidade. Belo Horizonte deu grande destaque à moda e concentrava muitos alfaiates e costureiras na produção de um visual de elegância para os moradores da cidade. Os judeus, no início como ambulantes, depois com suas lojas próprias, no comércio de tecidos finos, introduziram hábitos de elegância no vestir e na adequação a um novo estilo de requinte que a cidade exigia. A modernidade associa-se sempre à inovação contínua, o revolucionar-se sempre.

No nicho de moda, além das lojas de roupas prontas, muitos judeus foram comerciantes de tecidos vindos, principalmente, do Rio de Janeiro e São Paulo ou importados de fora do Brasil. As lojas grandes de departamentos, como tornaram-

\footnotetext{
${ }^{13}$ A Rua dos Caetés merece destaque pelo grande número de estabelecimentos de proprietários judeus que ali se concentrou. Para qualquer um que viveu em Belo Horizonte nos anos 1920 a 1950 é familiar a "rua dos turcos" ou "rua do comércio" como um dos locais privilegiados na memória da cidade. A Avenida Afonso Pena divide a Rua dos Caetés em duas partes distintas entre si. $O$ trecho que se estende da Avenida Amazonas ao final da Rua São Paulo foi o local de maior concentração de migrantes e, como espaço da sociabilidade, pode ser apontado como um lugar de estrangeiros.
} 
se A Futurista e a Sibéria, ambas de proprietários judeus, que na Europa e nos Estados Unidos representariam a popularização da moda, tornaram-se na capital mineira a referência de requinte e elegância. E assim, atendendo às necessidades da cidade, criando modas e, consequentemente, modos de viver da capital mineira, os judeus foram consolidando sua atuação nos espaços e se integrando.

Os dados construídos a partir do cruzamento de nomes das nossas listas das entidades e associações judaicas com os registros comerciais mostraram que os comércios de proprietários judeus na cidade somaram mais de cinquenta compostos por atividades no setor moveleiro, setor de decoração e (tecidos e moda), em maior quantidade, mas também no comércio de bijuterias e joias, material para construção e elétrico, eletroeletrônicos, brinquedos, alimentação (mercado, café e restaurante, banca de verdura/legumes), boates (dancings, cabarés, gafieiras), relojoaria, conserto e comércio de guarda-chuvas, construtoras, financeira e fábricas (colchão, roupas prontas).

Reforçando a singularidade, destacamos aqui a fundação da Escola Israelita $^{14}$, no fim de 1928, com início de funcionamento em fevereiro de 1929. A escola funcionou de 1929 até a década de 1960. Nos dois primeiros anos funcionava na Avenida João Pinheiro, 510, dentro da União Israelita de Belo Horizonte, depois na Rua Guajajaras 93, esquina com Rua Sergipe e, posteriormente, a escola passa a funcionar na Avenida João Pinheiro. Lá era ofertado o curso elementar e destacava-se pelo ensino das línguas do povo judaico (o ídiche e o hebraico) e a história do povo israelita (FALBEL, 1997). Nesses mais de trinta anos de existência15, a escola deu continuidade à formalização comunitária, já que ali

\footnotetext{
${ }^{14}$ A educação judaica é uma preocupação com a continuidade do grupo e suas características identitárias. Até a fundação da Escola, os filhos dos migrantes estudavam em escolas públicas e a educação comunitária não-formal fazia-se no cumprimento religioso em grandes festas e rituais de passagem de nascimento (brit milá), maioridade (bar mitzvá), casamento e morte. Com a fundação da Escola Israelita, é criado um espaço de educação comunitária, de socialização e reafirmação de pertencimento, com a preocupação central de preservar o judaísmo e difundir a cultura judaica.

${ }^{15}$ A Escola Israelita não desapareceu exatamente. Durante a década de 1960 a Escola Israelita (ou Escola Ídiche, como ficou conhecida por muitos) deu lugar a duas novas escolas: a Escola Theodor Herzl e a Escola Albert Einstein.
} 
estudaram os filhos dos pioneiros na organização comunitária judaica em Belo Horizonte $^{16}$, assim como as gerações subsequentes.

A escola funcionava numa forma mista, isto é, a responsabilidade e o pagamento dos professores eram divididos entre a comunidade judaica e o Estado, que tornou possível seu funcionamento ao ser reconhecido pelo governo como uma entidade educativa regular. Ao governo cabia a nomeação dos professores para as matérias exigidas no currículo de formação no país e à comunidade a responsabilidade pela contratação de professores de ídiche e hebraico.

A escola tinha, portanto, o aval do poder público que reconhecia as provas e registros definidos pelos padrões da legislação brasileira e que permitiu que ela tivesse uma continuidade, atravessasse as medidas restritivas de escolas de estrangeiros durante o Estado Novo varguista, que fechou várias escolas no país (CALVO, 2014, p. 192-193).

Os judeus, assim, marcaram seu espaço na cidade por meio da integração, constituindo uma comunidade singular em comparação com outras comunidades do Brasil e do mundo. Conviveram com a cidade e seus paradoxos e se adaptaram a eles, mantendo um diálogo entre a tradição e a emancipação que, embora fossem duas posições conflituosas nos espaços originais de onde os judeus vieram, articularam-se bem no espaço da nova cidade.

\section{Conclusão}

Reforçamos durante praticamente todo o artigo que cada comunidade judaica no Brasil e no mundo é diferente pela sua conjuntura de construção e da sua relação com o outro, reforçando seu caráter identitário e na cidade de Belo Horizonte uma singularidade no modo de ser judeu.

\footnotetext{
${ }^{16}$ Pode-se citar que na Escola Israelita estudaram os filhos de pioneiros já citados como Flora Lerman, Benzion Levy, Alberto Avritzer entre outros.
} 
Belo Horizonte ofereceu ao judeu uma cidade em estágio de formação, sob um modelo de modernização e consumo que ele veio a contribuir e ajudou a consolidar, lançando bases de um discurso inspirado no republicanismo (europeu) que dava sustentação ao processo de implantação do regime republicano que se instalava no país. A República como discurso na formação e formalização da cidade vai funcionar na atração e fixação dos judeus na capital mineira. Ela consagra, em primeiro lugar, um contexto de reformulação de um novo regime no seu formato moderno, pós-revoluções burguesas, como modelo de construção de um Estado que combatesse a tirania e refinasse novos códigos para inserção dos cidadãos.

O discurso do republicanismo e uma construção emancipatória e igualitária transformou em possibilidade ao promover a fixação do grupo judaico na cidade em sua composição, com destaque para os casamentos mistos - entre judeus e não judeus - , faz com que o judeu praticamente desapareça na cidade, tornando-se anônimo dentro e parte dela, sem destaque ou discriminação, integrado a modos de ser e de viver na capital mineira.

Apesar do imaginário político republicano, que se carrega no discurso, mas se esvazia na prática no Brasil e na cidade (pois reforçou até no próprio planejamento urbano a segregação e as formas de controle social excludentes), é por meio da utilidade, na composição de um comércio diferenciado e cosmopolita importante para o ideal moderno presente na concepção da capital mineira, que o judeu efetivamente consolida suas potenciais formas de integração e participação marcando sua atuação singular com a cidade de Belo Horizonte. Os judeus experimentaram características de cidade e formas de vinculação que deram sentidos de representação, integração e participação no modo de viver e crer.

Essas marcas vão materializar uma comunidade judaica belo-horizontina que nos traz uma ideia de ser tão discreta, a ponto de parecer invisível, diferentemente de outras cidades brasileiras. 


\section{REFERÊNCIAS}

BARTH, Fredrik. Grupos étnicos e suas fronteiras. In: STREIFF-FENART, Jocelyne;

POUTIGNAT, Philippe. Teorias da etnicidade. São Paulo: UNESP, 1997• p. 187-227.

BENCHIMOL, Samuel. Eretz Amazônia: os judeus na Amazônia. Manaus: Valer, 1998.

BLAY, Eva Alterman. Judeus na Amazônia. In: SORJ, Bila (Org.). Identidades judaicas no Brasil contemporâneo. Rio de Janeiro: Imago, 1997. p. 33-66.

BOTELHO, T. R. A migração para Belo Horizonte na primeira metade do século XX . Cadernos de História, Belo Horizonte, v. 9, n. 12, p. 11-33, 2007.

CALVO, Julia. Entre fazer a América e construir a cidadania: os judeus em Belo Horizonte nas primeiras décadas do século XX. Belo Horizonte, 2014. Tese (Doutorado) Programa de Pós-graduação Ciências Sociais, Pontifícia Universidade Católica de Minas Gerais. Disponível em:

<http://www.biblioteca.pucminas.br/teses/CiencSociais_CalvoJ_1.pdf>.Acesso em: 10 out. 2018

CARNEIRO, Maria Luiza Tucci. Brasil judaico: mosaico de nacionalidades. São Paulo: Maayanot, 2013.

CUNHA, Manuela Carneiro Da. Antropologia do Brasil: mito, história, etnicidade. São Paulo: Brasiliense; EDUSP, 1986.

FALBEL, Nachman. Estudos sobre a comunidade judaica no Brasil. São Paulo: FIESP, 1984 .

FALBEL, N. A imigração Judaíca no Brasil. Boletim do Instituto Histórico Israelita Mineiro, Belo Horizonte, v. 1, n. 1, 1997. p. 7- 28.

GEIGER, Pedro P. A América e a reconstrução da identidade judaica. In: LEWIN, Helena (Org.). Identidade e cidadania: como se expressa o judaísmo brasileiro. Rio de Janeiro: Programa de Estudos Judaicos, 2005. p. 289-300.

GOLDMANN, Nahum. O paradoxo judeu: memórias pessoais dos encontros históricos que moldaram o drama do judaísmo moderno. São Paulo: B’nai B’rith, 1984.

JULIÃO, Leticia. Belo Horizonte: itinerários da cidade moderna (1891-1920). In: DUTRA, Eliana de Freitas (Org.). BH: horizontes históricos. Belo Horizonte: C/Arte, 1996. p. 49-118.

LEWIN, Helena (Coord.). Judaísmo e cultura: fronteira em movimento. Rio de Janeiro: Imprimatur, 2013.

LEWIN, Helena. O olhar jovem sobre sua identidade judaica. In: SORJ, Bila (Org.). Judaísmo: memória e identidade. UERJ: Rio de Janeiro, 1997. p. 9-22. 
MAFFESOLI, Michel. O tempo das tribos: o declínio do individualismo nas sociedades tribais. Rio de Janeiro: Forense-Universitária, 1987.

MATOS, Henrique Cristiano. Um estudo histórico sobre o catolicismo militante em Minas, entre 1922 e 1936. Belo Horizonte: O Lutador, 1990.

METZGER, Bruce M. \& COOGAN, Michael D. Dicionário da Bíblia, vol. 1: as pessoas e os lugares, Rio de Janeiro: Jorge Zahar Ed, 2002.

PARREIRAS, Elisabeth Guerra. Belo Horizonte: uma economia de serviços. Cadernos de História, Belo Horizonte, v. 8, n. 10, p. 110-121, jul./dez. 2006.

PFEFFER, Renato Somberg. A comunidade judaica de Belo Horizonte: formação de uma identidade étnica particular numa sociedade diferenciada e plural. Belo Horizonte, 1993. Dissertação (Mestrado) - Departamento de Sociologia e Antropologia da Faculdade de Filosofia e Ciências Humanas da Universidade Federal de Minas Gerais.

PINSKY, Jaime. Origens do nacionalismo judaico. 2. ed. São Paulo: Ática, 1997.

PÓVOA, Carlos Alberto. Imigração judaica para o estado de Minas Gerais e os judeus na cidade de Uberlândia - MG. In: LEWIN, Helena. Judaísmo e modernidade: suas múltiplas inter-relações. Rio de Janeiro: Centro Edelstein de Pesquisas Sociais, 2009.

SIMMEL, Georg. O estrangeiro. Revista Brasileira da Sociologia da Emoção (RBSE), João Pessoa, v. 4, n. 12, p. 265-271, dez. 2005.

SORJ, Bernardo; GRIN, Monica (Org.) Judaísmo e modernidade: metamorfoses da tradição messiânica. Rio de Janeiro: Imago, 1997.

SORJ, Bernardo; GRIN, Monica (Org.). Judaísmo e modernidade: metamorfoses da tradição messiânica. Rio de Janeiro: Imago, 1993.

SORJ, Bila. Normalizando o povo judeu: a experiência da jewish colonization association no Brasil. In: SORJ, Bila. Identidades judaicas no Brasil contemporâneo. Rio de Janeiro: Imago, 1997. p. 87-102. 